\title{
Kısa Dönemli Hidrolojik Tahmin Sistemi Uygulaması
}

\author{
Gökçen Uysal ${ }^{1, *}$, Aynur Şensoy ${ }^{1} \oplus$, A. Arda Şorman ${ }^{1} \oplus$, M. Cansaran Ertaş ${ }^{2}$ \\ ${ }^{1}$ Eskişehir Teknik Üniversitesi (ESTÜ), Mühendislik Fakültesi, Inşaat Mühendisliği Bölümü, Eskişehir. \\ ${ }^{2}$ Erzurum Teknik Üniversitesi (ETÜ), Mühendislik ve Mimarlık Fakültesi, Inşaat Mühendisliği Bölümü, Erzurum.
}

\section{Özet}

Bu çalışmanın amacı kar erimesinin etkili olduğu dağlık memba havzaları için kısa dönemli akım tahmin sisteminin geliştirilmesidir. Çalıșma alanları olarak seçilen dağlık Fırat ve Seyhan Havzaları, yüksek su potansiyeli, bu potansiyeli besleyen kar erimeleri, mansapta büyük ve önemli su yapılarının bulunması ile ön plana çıkmaktadırlar. Yağış-akış ilişkisinin simülasyonu için dağllk bölge uygulamalarında literatürde yaygın olarak kullanılan HBV modeli seçilmiştir. Sayısal Hava Tahmin (SHT) verisi olarak Mesoscale Model 5 (MM5) ve Weather Research and Forecast (WRF) model sonuçları kullanılmıştır. Hidrolojik model parametrelerinin gözlenen yağış, sıcaklık ve akım verileriyle kalibrasyon/doğrulama işleminin yapılmasının ardından, analizleri yapılan SHT verilerinin girdi olarak kullanılması ile 1 ve 2 günlük akım tahminleri elde edilmiștir. Illeriye dönük akım tahminleri Delft-FEWS platformunda kapalı döngü şeklinde çalıştırılarak, geçmiş dönem tahmin simülasyonlarl gerçekleştirilmiş ve akım gözlemleri ile kıyaslanarak performans değerlendirmesi yapılmıştır. Elde edilen sonuçlar havzaların akış aşağısında bulunan su yapılarının daha verimli ișletilmesine ve böylece ülke ekonomisine katkı sağlayabilecektir.

\section{Anahtar Sözcükler}

Hidrolojik Modelleme, Sayısal Hava Tahmini, Akım Tahmini, Fırat ve Seyhan Havzası, Kar Erimesi

\section{Application of a Short-Term Hydrological Forecast System}

\begin{abstract}
This study aims to deploy a short term hydrological forecast system in snow dominated mountainous basins. The headwaters of Euphrates and Seyhan Basins, selected as study areas, stand out with their high water potential, snow melt feeding this potential and the presence of large and important water structures in the downstream. For the simulation of precipitation-runoff relationship, HBV model, a widely used model in the literature especially for mountainous regions, is utilized. Mesoscale Model 5 (MM5) and Weather Research and Forecast (WRF) model results are preferred as Numerical Weather Prediction (NWP) data. After calibration/validation of hydrological model parameters with observed precipitation, temperature and flow data, 1- and 2-day flow estimates are obtained using the analyzed NWP data as input. Hindcast simulations for the past period are implemented with a closed-loop structure on the Delft-FEWS platform, and performance evaluation is conducted by comparing them with streamflow observations. The results obtained may contribute to the more efficient operation of water structures located downstream of the basins and thus to the national economy.
\end{abstract}

$\underline{\text { Keywords }}$

Hydrological Modeling, Numerical Weather Prediction, Runoff Forecast, Euphrates and Seyhan Basins, Snowmelt Runoff

\section{Giriş}

Su kaynaklarının etkili bir şekilde işletilmesi, artan su talepleri ve küresel iklim değişikliği gibi etkenler sebebiyle gün geçtikçe daha da önem kazanmaktadır. Dağlık havzalar, sahip oldukları kar ve buz potansiyeli ile dünyada 1,6 milyar kişi için su kaynağı olmakla beraber (Immerzeel vd. 2002) veri toplama ve kar fiziği gibi zorlayıcı nedenlerle diğer havzalara göre daha az çalışılmış alanlardır. Türkiye'nin geniş yüzölçümü ve yükseklik değişimi göz önüne alındığında faydalanılabilecek su kaynakları ve gelişmeye devam eden hidroelektrik potansiyeli bulunmaktadır. Bu kaynakların doğru planlanması, sürekli izlenmesi ve verimli işletilmesi gerekmektedir. Ülkemizdeki önemli su yapılarının büyük bir çoğunluğu özellikle kar erimesinden yoğun olarak beslenen havzalarda bulunmaktadır. Bu nedenle, bu çalışmada Fırat ve Seyhan havzalarının dağlık memba kesimlerindeki iki havza pilot bölgeler olarak seçilmiştir. Fırat Havzası yüksek su potansiyeli, önemli su yapılarının bulunması ve sınır aşan sular kategorisindeki jeopolitik konumu nedenleriyle öne çıkarken, Seyhan Havzası ise yine yüksek su potansiyeli ve verimi bakımından, ayrıca özel sektör/kamuya ait işletmede ya da inşaat halinde bulunan ardışık su yapılarının varlığı ile önem arz etmektedir.

Kar erimesinin hesaplanmasında değişik yollarla uygulanan derece gün yöntemi, Dünya Meteoroloji Teşkilatının dağlık havzalardaki akımın hesaplanmasında kullanımını en çok önerdiği metotlarından biridir (WMO 1986).

\footnotetext{
* Sorumlu Yazar: Tel: +90 (222) 3213550 Faks: +90 (222) 3239501 
Dağlık alanlarda derece gün yöntemi ile akımın tahminini yapmak için Snowmelt Runoff Model (SRM) (Martinec 1975; Martinec vd. 1998) ve Hydrologiska Byråns Vattenbalansavdelning (HBV) (Bergström 1976; SMHI 1996) gibi çeşitli kavramsal modeller sıklıkla kullanılmaktadır (Johansson vd. 2001; te Linde vd. 2008; Şorman vd. 2009; Tahir vd. 2011; Şensoy ve Uysal 2012; Finger vd. 2015; Pangali Sharma vd. 2020).

Akım tahmin çalışmalarında öncül girdiler, ileriye dönük yağış ve sıcaklık verileridir. Sistemin performansı öncelikle bu verinin doğruluğuna bağlıdır. Bu veriler genellikle atmosferik model çıktısı olan Sayısal Hava Tahmin (SHT) verileridir ve sisteme girmeden önce tutarlılıklarının test edilip gerekirse çeşitli düzenlemelerin yapılması gereklidir. SHT verilerinin değerlendirilmeleri başı başına bir konudur ve farklı amaçlara göre farklı yaklaşımlar gerektirmektedir. Bu performans analizlerinin meteorolojik açıdan çok hidrolojik uygulama perspektifinden yapılması oldukça önemlidir. Öte yandan, atmosferik modellerin yağış tahmin becerisinin de kısıtlı olduğu (Cuo vd. 2011) vurgulanmaktadır. Sayısal yağış tahminleri belirsizlik içermekte ve üç tip hataya maruz kalmaktadır; yersellik, zamanlama, yağış olayının şiddeti (Habets vd. 2004). Bütün bunlar sayısal hava tahmin verilerinin akım tahminlerinde kullanılmasını kısıtlamakla birlikte meteorolojik gözlemlerdeki ve tahminlerdeki belirsizliklerin akım tahminlerine etkisinin belirlenmesine dair çalışmalar da gerekli ve geri beslemeler açısından önemli bulunmaktadır (Rossa vd. 2011; Shrestha vd. 2013; El Khalki vd. 2020).

Anderson vd. (2002) atmosferik Eta ve Mesoscale Model 5 (MM5) modellerinden elde edilen sıcaklık ve yağış değerlerini bir hidrolojik modele girdi olarak kullanıp 48 saatlik akım tahmin çalışması gerçekleştirmiştir. Atmosferik model verilerinin alansal çözünürlüğü iyileştikçe, daha iyi akım tahminlerinin bulunacağı sonucuna varılmıştır. Başka bir çalışma, Jónsdóttir ve Sórarinsson (2004) tarafından tahmin modelinden üretilen verilerin HBV hidrolojik modeliyle akım tahminlerinin kıyaslanmasıdır. Sonuçta, MM5 sayısal hava tahmin modelinin özellikle su bütçe planlamasında ve istasyonsuz havzalarda kullanılabilmesinde faydalı olabileceği değerlendirilmiştir. Benzer bir çalışma, Kunstmann ve Stadler (2005) tarafından Almanya'da bir havza için uygulanmış, MM5 model verisi WaSiM dağılımlı hidrolojik modele girdi olarak kullanılmış ve gözlemden \%21 daha az yağış üretmesine rağmen başarılı sayılabilecek akım tahminleri gerçekleştirmişlerdir. Givati vd. (2016) WRF/WRF-Hidro bütünleşik hidrometeorolojik model sistemini tek yönlü ve iki yönlü test ederek iki yönlü sistemin yağışı ve akım tahminlerini iyileştirdiğini göstermişlerdir. El Khalki vd. (2020) taşkın tahminleri elde etmek için Application of Research to Operations at Mesoscale (AROME), Aire Limited Dynamic Adaptation International Development (ALADIN) ve Weather Research and Forecasting (WRF) atmosfer modellerini dağlık Fas havzalarında kıyaslayarak WRF ve AROME modellerinin daha tutarlı tahmin verdiğini tespit etmişlerdir. Shirali vd. (2020) WRF verisi ile yapay zekâ modellerini kısa dönemli yağış, sıcaklık ve taşkın tahminlerinde kıyaslayarak, WRF verisi ile elde edilen sonuçların daha başarılı olduğunu tespit etmişlerdir. Bu bağlamda, atmosferik model tahmin çıktılarının hidrolojik model uygulamalarıyla bütünleştirilmesinin hala güncel ve önemli bir araştırma alanı olduğu söylenebilir.

Doğu Anadolu Bölgesine ait sınırlı sayıda ulusal çalışmalarda, havzaların su potansiyellerine dikkat çekerek nehir akım rejimlerinin incelenmesi; bu akımlara ait yıllık, aylık ve günlük modeller kullanarak ileriye dönük akım tahminlerinin önemi üzerinde durulmuştur. Şorman vd. (2009) HBV modelini uydu görüntüleri destekli uygulayarak MM5 model tahminleriyle Yukarı Fırat Havzası'nda başarılı sayılabilecek günlük akım tahmin simülasyonları gerçekleştirmişlerdir. Albostan ve Önöz (2010) Orta Fırat Havzasında kurak sezonları tespit ederek burada bulunan barajların işletme politikalarına katkıda bulunmak için Murat nehrinde düşük akımlara ait mevsimsellik indekslerini incelemişlerdir. Çakmak vd. (2010) yaptıkları çalışmada Dicle Havzası su potansiyelini vurgulayarak burada yer alan akım gözlem istasyonuna ait aylık ve yıllık akımların tahmini için hareketli ortalama (ARMA) stokastik modeller kurmuşlardır. Sen vd. (2011) Orta Fırat Havzası için günlük zaman adımlarında çalışan bir atmosfer-hidroloji modelleme sistemi geliştirmiştir ve özellikle 2004 yılında meydana gelen taşkını ve iklim değişikliklerini incelemeyi esas almıştır. Şensoy ve Uysal (2012) SRM modeli ile farklı kar çekilme eğrileri ve sayısal hava tahmin verileri ile akım simülasyonları gerçekleştirmişlerdir. Uysal vd. (2016) MODIS uydusu ve çok katmanlı algılayıcı modelini Yukarı Fırat havzasında uygulamışlardır. Şorman vd. (2019) uydu kar olasılık haritaları çıkartarak akım tahminlerinde ensemble modelleme yaklaşımı yapmışlardır.

Öte yandan Seyhan havzaları da akım potansiyeli ve hidroelektrik üretimi sebebiyle çeşitli yıllarda çalışma konusu olmuştur. Özdemir (2001) Kasım-Nisan ayları arasındaki taşkın potansiyeline dikkat çekmiştir. Bu sebeple 1980 yılı Seyhan taşkını için HEC-5 modeli ile simülasyon modeli kurmuş, bölgedeki barajların taşkın kontrolü ve hidroelektrik santralin elektrik enerjisi üretimlerindeki etkileşimlerini incelemiştir. Taşdemir (2009), Seyhan Havzası'nın bir alt havzası olan Sarız Çayı Havzası'nda hidrolojik modelleme ile akım simülasyonları yapmıştır. Selek vd. (2016) Seyhan havzası için iklim değişikliğine dirençlilik ve buna karşı etki analizleri incelemişlerdir. Buhan vd. (2019) ise bu bölgede geliştirilen akım tahmini ve optimizasyon çalışmalarını birleştirerek baraj işletme stratejileri ortaya koymuştur. Bu çalışmalar, sürekli su temini, taşkın kontrol yönetimi ve hidroelektrik santrallerinin işletilmesi için yapılacak akım tahminlerine duyulan ihtiyacı ve konunun önemini göstermektedir.

$\mathrm{Bu}$ çalışmanın amacı ise, seçilen iki örnek havzada sayısal hava tahmin verisini girdi alan bir hidrolojik model (HBV) ile 4 farklı yılda kısa vadeli (1-2 gün) akım tahmin çalışması yapmaktır. Çalışmaya değer katan yenilikçi tarafı ise uygulamanın Delft-Flood Early Warning System (Delft-FEWS) platformu altında tahminlerin her bir zaman aralığı (günlük) için ayrı ayrı çalıştırılarak gerçek-zamanlı tahmin sistemini kurgulayan bir yapıda tasarlanmasıdır. 


\section{Materyal ve Yöntemler}

Hidrolojik modeller meteorolojik parametreleri girdi alarak çalışırlar. İstenilen meteorolojik veriler ise hem zaman hem de alan bazında değişkenlik gösterir. Bu çalışmanın ilk kısmında hidrolojik model parametreleri, gözlem istasyonlarından elde edilen hidro-meteorolojik veriler kullanılarak kalibre edilmekte ve doğrulamaları yapılmaktadır. İkinci bölüm olan hidrolojik tahmin kısmında ise sayısal hava tahmin verisi olan yağış ve sıcaklık değerleri kalibre edilmiş hidrolojik modele girdi olarak verilmektedir. SHT şu anki havanın birkaç gün sonrasına kadar olacak durumunu atmosferik modeller yardımıyla tahmin etme tekniğine verilen isimdir. Hidrolojik akım tahminlerindeki doğruluk, meteorolojik tahmin güvenilirliğine çok bağlıdır. Bu bağlamda, akım tahmin çalışmalarına başlamadan tahmin verileri yer gözlemleri ile karşılaştırılmış ve çalışılan havzaya uygun düzeltme yöntemleri uygulanmıştır. İstenilen meteorolojik verilerin zamansal, alansal ve türsel bazda değişkenlik göstermesinden dolayı değerlendirmeler zorlayıcı olabilmektedir. Bu tip veriler genellikle hücresel bazlı olup farklı performans kriterleri ile test edilebilmektedir.

Çalışma genel olarak; çalışma alanlarının seçimi, sayısal hava tahmin verisi analizleri ve hata düzeltmesi, hidrolojik modelleme ile modele entegre gerçek zamanlı tahmin tekniklerini içermektedir. Öncelikle, seçilen MM5 ve WRF sayısal hava tahmin verileri (yağış ve sıcaklık) yer gözlemleri ile karşılaştırılmıştır. Sonrasında ise gerçek zamanlı tahmin modeli Delft-FEWS alt yapısında kurgulanarak kalibre edilmiş ve doğrulanmış hidrolojik modelin (HBV) geçmiş döneme ait bir süreçte gerçek zamanlı tahmin performansı değerlendirilmiştir. Çalışma yapısının adımlarını göstermek için Şekil 1'deki akış diyagramı sunulmuştur.

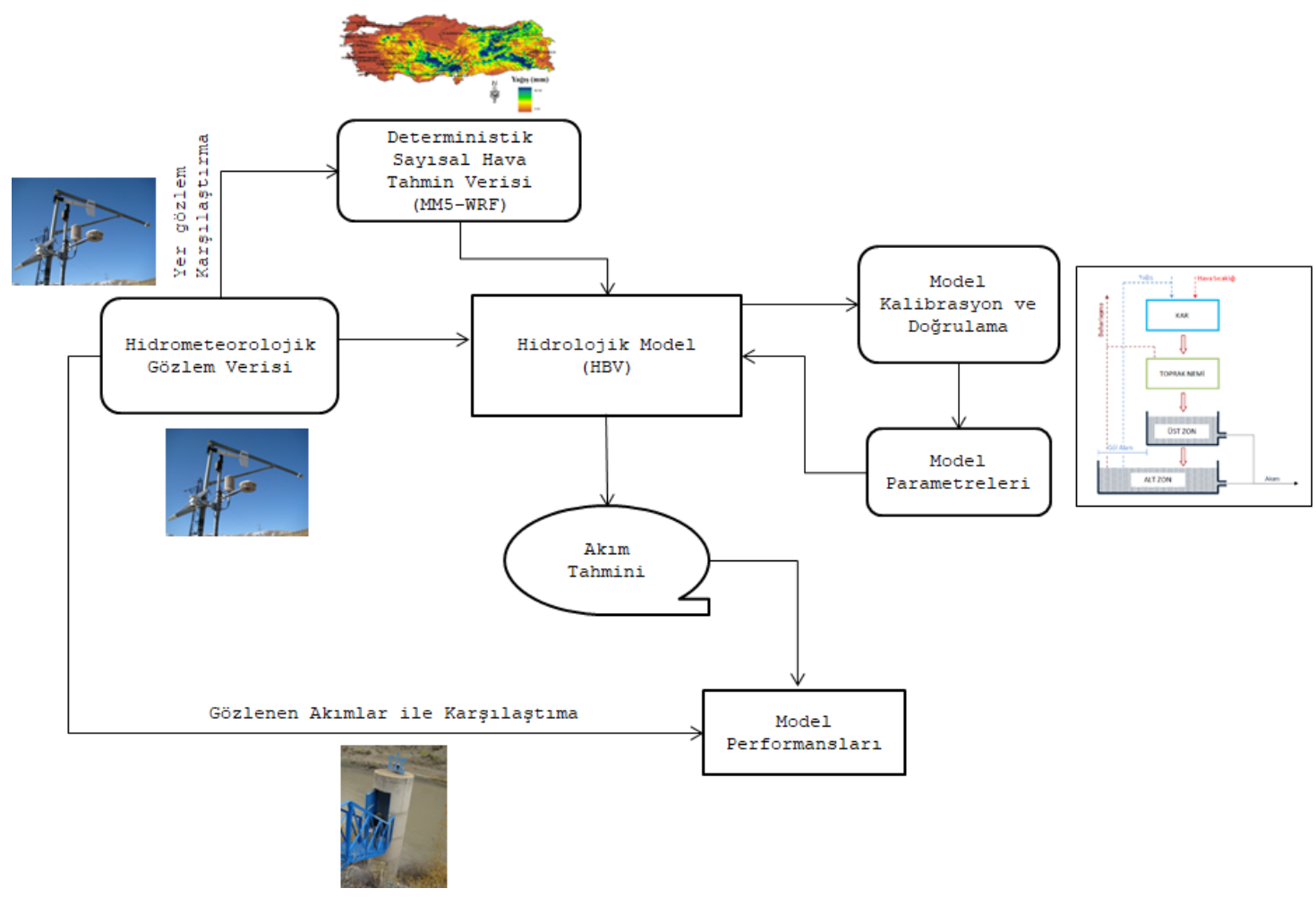

Şekil 1. Çalışma akış diyagramı

\section{1. Çalışma Alanları}

Araştırmada çalışılmak üzere Fırat ve Seyhan Nehirlerinin doğduğu dağlık bölgelerde iki örnek havza seçilmiştir (Şekil 2). Bunlardan ilki Fırat Nehrinin önemli kolu olan Karasu (Yukarı Fırat) nehrinin, diğer ise Seyhan havzasındaki Göksu nehrinin üst kotunda yer almaktadır. Havza çıkışlarında yer alan ve DSİ tarafından işletilen Akım Gözlem İstasyonları (AGİ) Karasu nehri üzerinde Kemah istasyonu (AGİ No: E21A019, 10.275 km²), Göksu Nehri üzerinde Çukurkışla istasyonudur (AGİ No: E18A024, 1.526 km²). Bahsi geçen iki havza, çalışmanın kalan kısmında Karasu ve Çukurkışla Havzaları olarak anılacaktır.

Çalışma havzaları için belirlenen çıkış noktalarına göre Coğrafi Bilgi Sistemleri (CBS) yardımıyla çeşitli mekansal analizler yapılmıştır. Sayısal yükseklik modeli (DEM) haritalarına göre Karasu Havzasının yüksekliği $1125-3500$ m ve Çukurkışla Havzasının yüksekliği 1350-3000 m arasında değişmektedir. Havzalar kar modelleme çalışmalarında kullanılmak üzere uygun yükseklik aralıklarına bölünmüştür. Karasu ve Çukurkışla Havzaları için ortalama hipsometrik yükseklik değerleri sırasıyla 1983 ve 1710 m olarak belirlenmiştir. Hazırlanan arazi kullanım haritalarına göre havza alanlarının \%90'dan fazlası tarımsal, mera ve çıplak alandan oluşmaktadır. 
İki havza için de havza alanlarının \%45-50'den fazlasının \%15 ve üzeri eğime sahip olduğu görülmektedir. Akım gözlem istasyonlarından toplanan veriler, toplam su hacimlerinin Karasu için yaklaşık \%60-70'i ve Çukurkışla için ise yaklaşık \%50-60'ının Mart-Haziran aylarında geldiğini göstermektedir. Bu da havzaların önemli oranda kar erimesinden beslendiğine işaret etmektedir.

Ölçüm ağı bakımından Karasu havzasının görece olarak daha zengin bir ölçüm ağına sahip olduğu anlaşılmaktadır. Bunun sebebi, Karasu Havzasının uzun yıllar çeşitli projelerde örnek havza olarak çalışılmış olmasıdır.

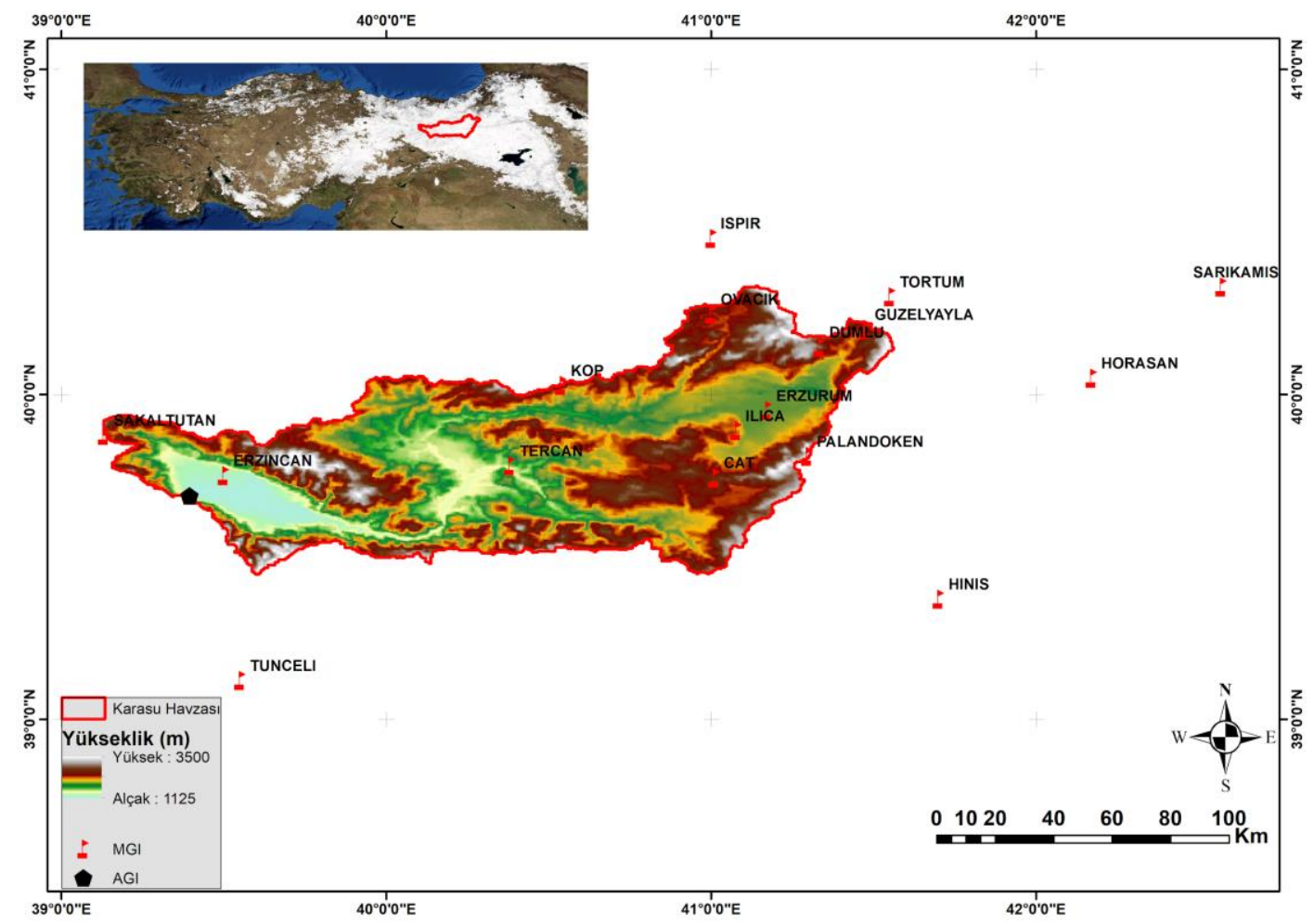

(a)

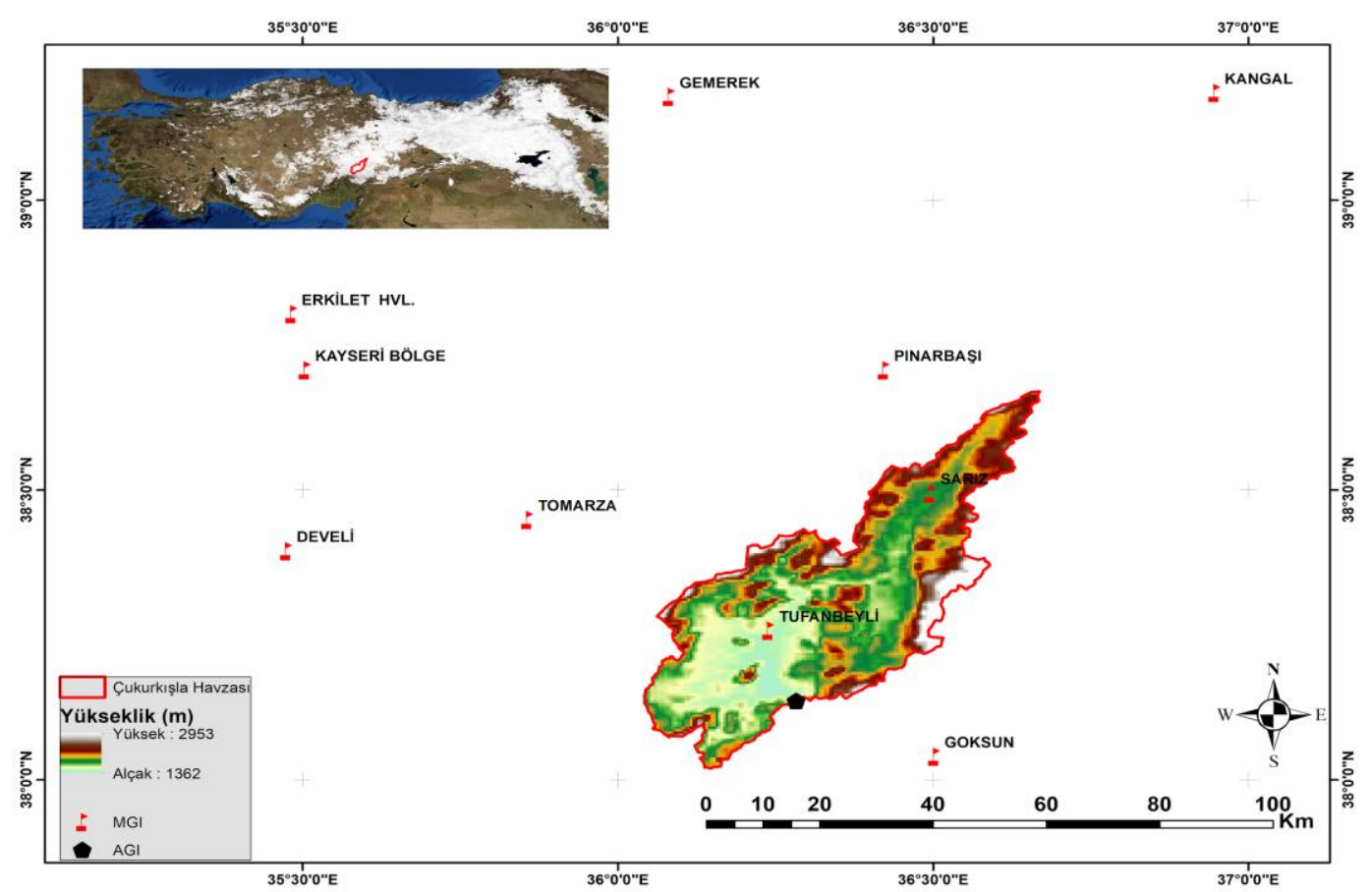

(b)

Şekil 2: Meteoroloji (MGI) ve Akım (AGi) Gözlem Istasyonları : (a) Fırat, (b) Seyhan 


\subsection{Sayısal Hava Tahmin (SHT) Verisi}

Meteoroloji Genel Müdürlüğü (MGM) Türkiye'deki hava tahminlerini ilgili kullanıcılara veri sağlayan kurumdur. Türkiye, Avrupa Orta Ölçekli Hava Tahmin Merkezi (European Center for Medium Range Weather Forecasts, ECMWF) üye ülkelerinden birisidir. MGM, 3 ile 6 saat arasında değişen ve $0,5^{\circ}(\sim 45 \mathrm{~km})$ yersel hücre çözünürlüğü olan orta-ölçekli hava tahmin değerlerini ECMWF'den temin ederek, bu verileri kendi bilgisayarlarında belirlenen sınır koşullar çerçevesinde günde dört defa çalıştırarak $(00,06,12,18$ UTC saatleri) yersel hücre çözünürlüğü $4,5 \mathrm{~km}$ ve tahmin periyodu 72 saat olan hava tahminleri üretmektedir. MGM, 2012 yılına kadar Mesoscale Model 5 (MM5) verileri üretirken, 2013 yılından itibaren ise teknolojik gelişmelere paralel olarak tutarlılığı arttırmak amacıyla Weather Research and Forecasting (WRF) modeline geçmiştir (Şekil 3). Bu çalışmada, MGM tarafından üretilen deterministik SHT verisi özel bir protokol çerçevesinde temin edilerek (2012 yılı için MM5, 2013 - 2015 yılları arası WRF modelinden 48 saat ileriye dönük olarak) kullanılmıștır. MGM tarafindan kullanılan tahmin modelleri:

i) Mesoscale Model 5, MM5 (Orta Ölçek Model 5): MM5 hava tahmin modeli (Şekil 3a), Amerika Birleşik Devletleri'nde bulunan NCAR (National Center for Atmospheric Research) tarafindan geliştirilen ve birçok meteoroloji örgütü ve üniversiteler tarafindan tercih edilmiş olan bir modeldir.

ii) Weather Research and Forecasting, WRF (Hava Tahmin ve Araştırma): WRF hava tahmin modeli (Şekil 3b), operasyonel öngörüler kadar atmosferik araştırmalara yanıt verebilecek yeni nesil bir sayısal hava tahmin modelidir. Bu model birden fazla dinamik merkez koduna ve veri asimilasyonu sistemine sahiptir. WRF Modeli, MM5 modelinin geliştirilerek yenilenmiş bir versiyonudur (URL-1 2020).
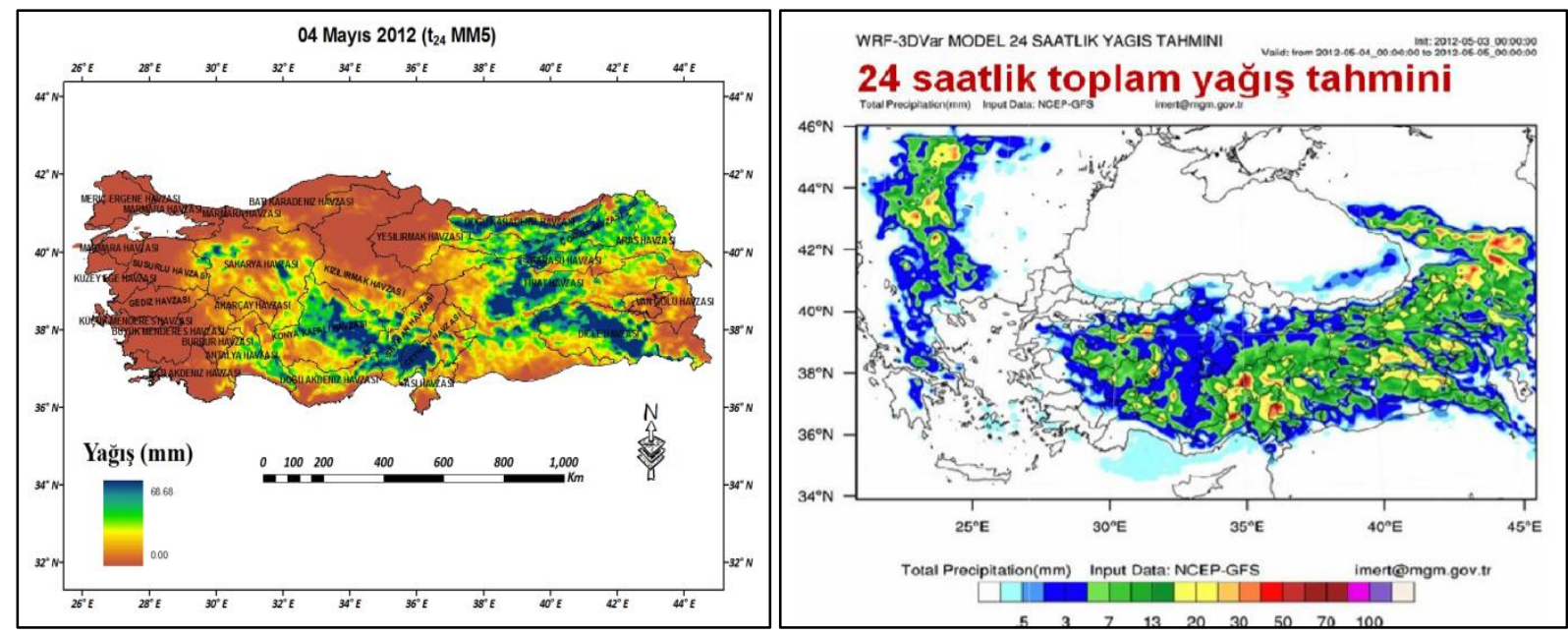

Şekil 3: 24-saatlik toplam yağış tahmini a) MM5 b) WRF

Atmosferik-hidrolojik model entegrasyonu yapılmadan önce, SHT verilerinin yer gözlem verileriyle karşılaştırılması gerekmektedir, çünkü MM5 ve WRF model verileri üretilirken belirli altlıklar kullanmaktadır. Bunlar arasında arazi kullanım haritası ile yükseklik bilgileri de bulunmaktadır. Arazinin dağlık olduğu ve yüksekliklerin çok değişkenlik gösterdiği havzada tahmin verilerinin yer ölçüm istasyonlarından kaydedilen değerlerle karşılaştırılması ve ilişkilerinin gözden geçirilmesi önemlidir. Sıcaklık verileri; saatlik SHT verilerinin ortalamaları alınarak, yağış verileri; konvektif ve konvektif olmayan günlük tahmin değerleri toplanarak günlük veri formatına dönüştürülmüştür. Karşılaştırma için havza sınırları içerisine düşen gözlem ve SHT verilerinin ortalamaları kullanılmıştır.

Son yıllarda tahmin verilerinin değerlendirilmeleri için farklı bilimsel metotlar ortaya konmuştur (Casati vd. 2008; Jolliffe ve Stephenson 2012). Sıcaklık verisi, gerek daha sürekli olması gerekse yükseklikle çok yakından değişim göstermesi teknolojik olarak gelişen atmosferik modeller tarafından daha başarılı şekilde tahmin edilebilmekte ve literatürde önerilen çeşitli istatistiksel yöntemlerle daha doğru biçimde düzeltilebilmektedir (Durai ve Bhradwaj 2014). Literatürde tavsiye edilen çeşitli güncel yöntemler (en iyi sistematik hata, doğrusal regresyon, hareketli ortalama, en yakın komşuluk) incelenmiş ve bu çalışmada sıcaklık SHT verisi için en uygun olarak doğrusal regresyon düzeltme yöntemi seçilmiştir.

Yağış verisi ise sıcaklığa kıyasla daha düzensiz, daha bölgesel ve ayrıca farklı tiplerde görülmektedir. Bu sebeplerden dolayı atmosferik modeller yağış SHT verilerinde hem miktarsal hem de zamansal açıdan daha fazla belirsizlik içermektedir. Çalışmada yağış tahminleri için çeşitli düzeltme yöntemleri denenmesine rağmen anlamlı bir iyileşme gözlenmediğinden yağış SHT verilerinde herhangi bir düzeltme işlemi yapılamamıştır. Hamill (1999), hücre yağış tahminlerini değerlendirmek için ihtimal tablolarına dayalı skorların kullanılmasını önermiştir. Bu skorlar, ulusal hava tahmin merkezleri tarafindan yağış tahminlerinde sıklıkla kullanılan bir tutarlılık ölçüsüdür (Gallus ve Segal 2001; Ebert vd. 2003; Mailhot vd. 2006; Belair vd. 2009; Ghajarnia vd. 2015; Sharifi vd. 2018), bu nedenle çalışmada yağış verilerinin değerlendirilmesi için benzer bir yaklaşım benimsenmiştir. 


\subsection{Hidrolojik Modelleme ve Tahmin Sistemi}

Dağlık alanlardaki biriken kar potansiyeli erime sezonunun başlamasıyla nehir akımlarında ve dolayısıyla baraj doluluk oranlarında artış meydana getirmektedir. Oluşacak akımların debisini, hacim miktarını ve zamanlamasını belirleyebilmek için hidrolojik modellere ihtiyaç duyulmaktadır. Bu çalışmada amaçlanan kar erime sezonunda yapılacak günlük akım tahminleridir. Bu tahminleri gerçekleştirebilmek için arazi ölçümlerinin ve farklı sayısal hava tahmin verilerinin hızlı bir şekilde işlenerek hidrolojik modellere girdi sağlaması gerekmektedir.

Çalışmada kullanılan HBV modeli, İsveç Meteoroloji ve Hidroloji Enstitüsü (SMHI) tarafından geliştirilmiştir (Bergström 1976). Literatürde geniş bir kullanıma sahip olan HBV modeli, farklı iklim koşullarında ve küçük araştırma havzalarından kıtasal ölçek boyutlarına kadar 90 ülkede uygulanmıştır (Bergström ve Lindström 2015).

HBV modeli, bir hidrolojik havzanın alt havzalara bölünerek veya yükseklik aralıklarına göre ayrılarak hidrolojik modelleme yapabilmesinden dolayı yarı dağılımlı bir kavramsal model olarak tanımlanabilir. Bu kısımda, modelleme yapılacak olan havzanın yükseklik-alan dağılımı ve arazi kullanımı gibi özellikleri önem kazanmaktadır. HBV kavramsal modeli, dağlık alanlarda derece-gün yöntemini kullanarak yağış-akış ilişkisini kurmaktadır.

Model genel olarak kar modülü, toprak nemi modülü ve akım modülü olmak üzere üç ana kısımdan oluşmaktadır. Modüllerin HBV modeli içindeki çalışma akış diyagramı Şekil 4’te görülmektedir. İlk olarak kar modülü hava sıcaklığını eşik hava sıcaklığı (TT) ile kıyaslayarak yağışın yağmur ya da kar olması durumunu belirler. Eğer kar ise biriktirme yapar ve erime sıcaklığına (TM) göre kar erimesinin başlayıp başlamayacağına karar verir. Daha sonra toprak nemi modülü, yağışı veya kar erimesini kar modülünden girdi olarak alır ve toprakta suyun depolanmasını, gerçek buharlaşma-terlemeyi ve akım modülüne çıktı olarak verilen yağışla gelen net akım miktarını hesaplar. Akım modülü, toprak nemi modülünde üretilen net yağışı akıma dönüştürür. Bu akım, üst bölge ve alt bölge olmak üzere iki kısımda son akışı belirler. Üst bölge direkt akışa geçen yüzey ve ara akışı (hızlı akış) temsil ederken, alt bölge taban akışını (yavaş akış) temsil eder. HBV modeli, her bir modülün sonucuna göre en basit anlamda Denklem 1'e göre hesap yaparak akış değerini hesaplar.

$P-E-Q=\frac{d}{d t}[S P+S M+U Z+L Z+g o ̈ l]$

“P”, yağıș (mm); “E”, buharlaşma-terleme (mm); “Q”, akım (mm); “SP”, kar modülü; "SM”, toprak nemi modülü; "UZ", üst akım modülü; "LZ”, alt akım modülü; "göl” ise göl hacmini ifade eder.

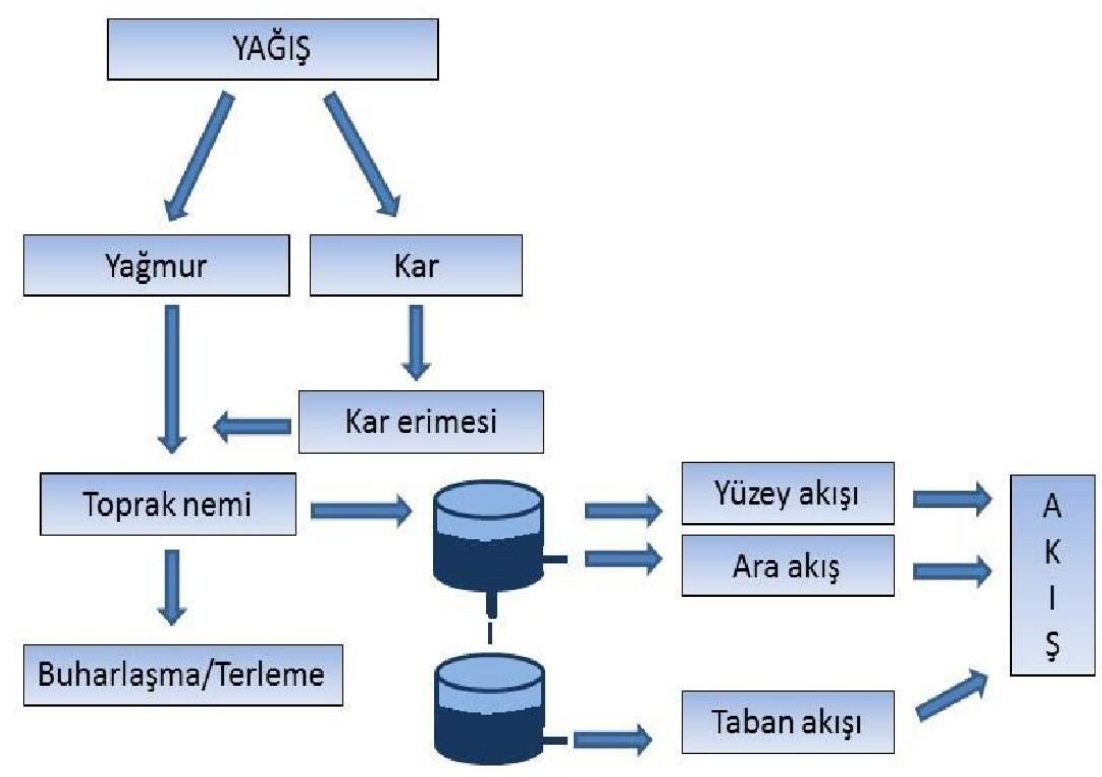

Şekil 4: HBV modelinin çalışma akış diyagramı

Hidrolojik modelleme için yer gözlem verisi kullanılarak hazırlanan model girdilerinden sonra model parametrelerinin kalibrasyonu (ayarlanması) ve doğrulanması gerekmektedir. Bu aşamada her havza için veriye göre çeşitli periyotlar belirlenmiştir (Tablo 1). Kalibrasyon/doğrulama sonucunda elde edilen parametre setleri ile daha sonra ortak bir periyotda SHT verisine (MM5/WRF) dayalı kısa vadeli (1-2 gün) akım tahmin çalışması yapılmıştır. 
Geçmiş dönem tahmin simülasyonu kurgusu her biri başlangıç [T0] anına kadar ısıtılan modelin seçilen zaman ölçeğinde (günlük) ileriye dönük tahmin yapması ve her adımda bir önceki durum değişkenlerini güncelleyerek sistemin çalıştırılması şeklinde (kapalı döngü) gerçekleştirilmiştir.

Tablo 1: Model uygulama aralıkları (su yılı bazında)

\begin{tabular}{|c|c|c|c|}
\hline Havza & Kalibrasyon Dönemi & Doğrulama Dönemi & Tahmin Dönemi \\
\hline Karasu Havzası & $2001-2008$ & $2009-2014$ & $2012-2015$ \\
\hline Çukurkışla Havzası & $2005-2010$ & $2011-2014$ & $2012-2015$ \\
\hline
\end{tabular}

Çoklu veri, güncellenen model uygulaması ve veri dönüşümü gibi işlemleri gerektiren gerçek zamanlı tahmin sistemleri için karar destek platformlarına ihtiyaç duyulmaktadır. Bu amaçla, Delft-FEWS çeşitli tahmin merkezleri tarafından dünyada birçok bölgede farklı çalışma ve araştırma örneklerinde kullanılmaktadır (Werner vd. 2013). DelftFEWS özellikle taşkın tahmini, kuraklık ve mevsimsel tahmin, su kaynaklarının gerçek zamanlı işletilmeleri gibi amaçlarda uzman bir veri işleme ve model entegrasyonu sağlayan bilgisayar yazılımıdır. Bu yazılım, ücretsiz olarak indirilebilir eXtensible Markup Language (XML) tabanlı bir yapıdan oluşmakta ve ihtiyaç duyulan sistemin kullanıcı tarafından konfigürasyonun yapılmasına imkân vermektedir. Çalışmada da elde edilen verilerin işlenmesi, hidrolojik model entegrasyonu ile geçmiş dönem tahmin simülasyon sistemi kurgusu Delft-FEWS platformunda çalıştırılmıştır.

\subsection{Performans Kriterleri}

Akım ve SHT verilerinin sonuçları farklı performans kriterleri ile değerlendirilmiştir. Elde edilen karşılaştırmalara ait doğrusal ilişkiler kullanılarak sıcaklık verilerinde düzeltme yapılmıştır. Yapılan düzeltmeler, yer gözlemleri ile karşılaştırılarak katkıları sorgulanmıştır. Buradaki bir diğer amaç da geçmiş yıllara ait düzeltme parametrelerini belirleyerek gerçek zamanlı akım tahminlerinde SHT verilerindeki belirsizliği azaltmaya çalıșmaktır.

- Modellenen akımların AGI verileri ile karşılaştırmalarında: Pearson korelasyon katsayısının karesi olan belirginlik katsayısı $\left(\mathrm{R}^{2}\right)$, Nash-Sutcliffe (NSE) model verimliliği, ortalama mutlak hata (MAE) ve ortalama

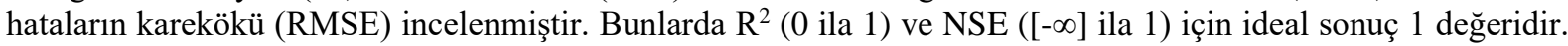
Diğer iki hata ölçütünün (RMSE ve MAE) ise olabildiğince düşük olması beklenilir.

$R^{2}=\left[\frac{\sum_{t=1}^{n}\left(Q_{m}^{t}-\bar{Q}_{m}\right)\left(Q_{o}^{t}-\bar{Q}_{o}\right)}{\sqrt{\sum_{t=1}^{n}\left(Q_{m}^{t}-\bar{Q}_{m}\right)^{2}} \sqrt{\sum_{t=1}^{n}\left(Q_{o}^{t}-\bar{Q}_{o}\right)^{2}}}\right]^{2}$

$N S E=1-\frac{\sum_{t=1}^{n}\left(Q_{o}^{t}-Q_{m}^{t}\right)^{2}}{\sum_{t=1}^{n}\left(Q_{o}^{t}-\bar{Q}_{o}\right)^{2}}$

$R M S E=\sqrt{\frac{\sum_{t=1}^{n}\left(Q_{m}^{t}-Q_{o}^{t}\right)^{2}}{n}}$

$M A E=\frac{\sum_{t=1}^{n}\left|Q_{o}^{t}-Q_{m}^{t}\right|}{n}$

$Q_{m}^{t}$ model değeri, $Q_{o}^{t}$ gözlem değeri, $\bar{Q}_{m}$ model ortalaması, $\bar{Q}_{o}$ gözlem ortalaması, $n$ veri seti sayısını ifade eder.

- SHT verisinin yer gözlemleri ile karşılaştırmalarında: Sıcaklık veri seti için; minimum, maksimum, ortalama sıcaklıklar ve yer gözlemleri ile doğrusal uyumları için $\mathrm{R}^{2}$ değerleri; yağış veri seti için ise veri süreksizliği nedeniyle "olası ihtimaller tablosu" ve buna uygun indeksler incelenmiştir.

Olası ihtimal tablosu tahmin ve gözlem değerleri arasında bir eşik değerine dayalı 4 durumu içerir. Verilen bir eşik yağış değeri için, tahminler 4 ayrı küme içeren kapsamlı olaylar ihtimal tablosuna ayrılır. (a) hem tahmin değeri hem de gözlenen değerlerin eşiğe eşit ve eşikten büyük olduğu olay sayısı, "yakalananlar", (b) tahmin değerinin eşiğe eşit veya eşikten büyük olduğu durumlarda gözlenen değerlerin eşikten küçük olduğu olay sayısı, "yanlış alarm”, (c) tahmin değerinin eşikten küçük olduğu durumlarda gözlenen değerlerin eşiğe eşit veya eşikten büyük olduğu olay sayısı, "kaçırılanlar" ve (d) hem tahmin hem de gözlenen değerin eşikten düşük olduğu olay sayısı "eşik altı" olarak nitelendirilmektedir. Bu ihtimaller Tablo 2'de gösterilmiştir. Çalışmada, yalnızca farklı yıllar değil, farklı havzalar da kıyaslandığından, olası ihtimal skorları bölüm sonunda yakalama ve yanlış alarm oranları ile de ifade edilerek havzalar arası kıyaslama yapılmaya çalışılmıştır. 
Tablo 2: Olası olaylara ait ihtimal tablosu

\begin{tabular}{|c|c|c|c|}
\hline \multirow{2}{*}{} & & \multicolumn{2}{|c|}{ Gözlem } \\
\cline { 3 - 4 } & & Evet & Hayır \\
\hline \multirow{2}{*}{ Tahmin } & Evet & $\mathrm{a}$ & $\mathrm{b}$ \\
\cline { 2 - 4 } & Hayır & $\mathrm{c}$ & $\mathrm{d}$ \\
\hline
\end{tabular}

a: yakalanan, b: yanlış alarm, c: kaçırılan, d:eşik altı

Seçilen dört farklı eşik yağış $(0,1 ; 1 ; 2 ; 5 \mathrm{~mm})$ değeri için her bir parametre (a, b, c ve d) hesaplanmış ve Algılama Olasılığı (AO) ile Yanlış Alarm Oranı (YAO) hesaplanmıştır. Ayrıca Sapma Oranı (SO) da incelenmiştir. SO’nun 1 (bir) değeri mükemmel modeli temsil ederken, 1'den uzaklaşan her değer farkları ortaya koymaktadır.

$$
\begin{aligned}
& \mathrm{AO}=\frac{a}{a+c} \\
& \mathrm{YAO}=\frac{b}{a+b} \\
& \mathrm{SO}=\frac{a+b}{a+c}
\end{aligned}
$$

\section{Bulgular ve Tartışma}

Bu bölümde elde edilen bulgular üç alt başlıkta sunulmuştur. İlk bölüm hidrolojik model kalibrasyon ve doğrulama sonuçlarını gösterirken, ikinci bölümde SHT verisinin yer gözlemleriyle karşılaştırılmasını ele almakta ve son bölüm ise SHT verisinin hidrolojik modele girdi yapılarak akım tahminlerinin üretilmesi ve başarısını değerlendirmektedir.

\subsection{Hidrolojik model sonuçları}

Her iki havza için yer verisinden dolayı farklı periyotlarda yürütülen modelleme çalışmalarında başarılı sayılabilecek sonuçlar elde edilmiştir. Model performansları Tablo 3'de, kalibre edilen model parametreleri Tablo 4'de sunulmuştur. Sonuçlara göre kalibrasyon döneminde 0,8 ve doğrulama döneminde 0,7 değerinin üzerinde çıkan NSE performansları hidrolojik modele olan güveni artırmaktadır. Model parametreleri ise literatürde önerilen aralıklarda yer almakta ancak havzaların farklı bölge ve meteorolojik koşulları göz önüne alındığında değişiklik gösterebilmektedir.

Tablo 3: Hidrolojik model NSE performansları

\begin{tabular}{|c|c|c|}
\hline Havza & Kalibrasyon Dönemi & Doğrulama Dönemi \\
\hline Karasu Havzası & 0,85 & 0,73 \\
\hline Çukurkışla Havzası & 0,84 & 0,78 \\
\hline
\end{tabular}


Tablo 4: Hidrolojik model parametreleri

\begin{tabular}{|c|c|c|c|c|}
\hline Parametre & Birim & Kisaltma & $\begin{array}{l}\text { Karasu } \\
\text { Havzası }\end{array}$ & $\begin{array}{c}\text { Çukurkışla } \\
\text { Havzası }\end{array}$ \\
\hline Yağmur düzeltme faktörü & --- & RFCF & 1,1 & 0,7 \\
\hline Kar düzeltme faktörü & --- & SFCF & 0,74 & 0,70 \\
\hline Eşik sıcaklığı & ${ }^{\circ} \mathrm{C}$ & TT & 2,256 & $-0,793$ \\
\hline Derece-gün faktörü & $\mathbf{m m} /$ gün $^{\circ} \mathrm{C}$ & CFMAX & 1,875 & 5,000 \\
\hline Erime sıcaklığı & ${ }^{\circ} \mathrm{C}$ & TM & $-0,101$ & $-0,099$ \\
\hline Toprak parametresi & --- & BETA & 1,18 & 0,54 \\
\hline Kapiler akım & $\mathrm{mm} /$ gün $^{0} \mathrm{C}$ & CFLUX & 0,3 & 0,2 \\
\hline Tarla Kapasitesi & $\mathbf{m m}$ & FC & 131 & 202 \\
\hline Potansiyel buharlaşma-terleme limiti & --- & LP & 0,477 & 0,900 \\
\hline Çekilme parametresi & --- & ALPHA & 0,0367 & 0,0001 \\
\hline Hızlı akış katsayısı & 1/gün & $\mathbf{K}$ & 0,0434 & 0,0974 \\
\hline Yavaş akış katsayısı & 1/gün & K1 & 0,0024 & 0,0167 \\
\hline Derin sızma & $\mathrm{mm} / \mathbf{g u ̈ n}$ & PERC & 1,125 & 2,166 \\
\hline
\end{tabular}

\subsection{SHT verilerin incelenmesi ve performans analizleri (MM5, WRF)}

Öncelikle, 2012 yılı MM5 ile 2013-2015 WRF günlük ortalama sıcaklık SHT verileri gözlenmiș değerlerle karşılaştırılmış, elde edilen ilişkiler ile bir düzeltme yapılmış ve düzeltilmiş veriler de ayrıca incelenmiştir (Tablo 5). İyileştirmeler doğrusal ilişkilerle yapılmış, sonucunda $\mathrm{R}^{2}$ ölçütünde değişiklik olmamasına rağmen ortalama, minimum ve maksimum sıcaklıklar ile istatistiksel katsayılar gözlenene yaklaşmıştır. Ortalama sıcaklıklar açısından Çukurkışla havzasında sıcaklık farkları Karasu havzasına göre daha düşüktür.

Düzeltme katsayıları her bir yıl için yapılsa da hidrolojik model uygulamalarında, o yıla ait düzeltme parametreleri önceden bilinemeyeceğinden bir önceki yıla ait düzeltme katsayıları kullanılarak daha gerçekçi bir yaklaşım yakalanmaya çalışılmıştır. Elde edilen sonuçlara göre, geçmiş yıllarda 2013-2015 WRF sıcaklık verisi yer gözlemleri ile ilişki açısından 2012 MM5 sıcaklık sonuçları gibi yüksek tutarlılık sergilemektedir. MM5 değerleri düşük sıcaklıklarda gözlenenden yüksek, yüksek sıcaklıkların olduğu aylarda gözlenenden daha düşüktür. WRF tahmin değerleri ise düşük ve yüksek sıcaklıklardaki aylarda sürekli olarak gözlenenden daha düşüktür. Bu ise düzeltmelerde daha tutarlı ve iyi sonuçlara sebep olmuştur. Genel olarak, WRF sıcaklık verisi MM5'e kıyasla daha yüksek tutarlılık vermekte ve tüm sezonda göreceli sabit bir ilişki ortaya koymaktadır. 
Tablo 5: SHT sıcaklık verisi karşılaştırmaları, MM5 (2012) ve WRF (2013-2015)

\begin{tabular}{|c|c|c|c|c|c|c|c|c|c|c|c|c|}
\hline \multirow{2}{*}{ Havza } & \multirow{2}{*}{$\begin{array}{c}\text { SHT } \\
-\end{array}$} & \multirow{2}{*}{$\begin{array}{c}\text { Yıl } \\
-\end{array}$} & \multirow{2}{*}{$\begin{array}{c}\begin{array}{c}\text { Yer } \\
\text { Gözlem } \\
\text { - SHT } \\
\text { ilişkisi }\end{array} \\
\mathbf{R}^{2}\end{array}$} & \multicolumn{3}{|c|}{ Ham SHT } & \multicolumn{3}{|c|}{ Yer Gözlem } & \multicolumn{3}{|c|}{ Düzeltilmiş SHT } \\
\hline & & & & Orta. & Min. & Mak. & Orta. & Min. & Mak. & Orta. & Min. & Mak. \\
\hline \multirow{4}{*}{ Karasu } & MM5 & 2012 & 0,97 & 5,2 & $-9,3$ & 18,1 & 4,4 & $-13,7$ & 19,0 & 4,4 & $-14,0$ & 20,8 \\
\hline & WRF & 2013 & 0,91 & 3,6 & $-14,3$ & 14,9 & 5,6 & $-12,1$ & 15,7 & 5,6 & $-9,2$ & 15,0 \\
\hline & WRF & 2014 & 0,99 & 6,4 & $-11,4$ & 16,8 & 6,7 & $-11,8$ & 15,4 & 6,7 & $-9,3$ & 15,9 \\
\hline & WRF & 2015 & 0,98 & 4,5 & $-12,4$ & 17,6 & 5,7 & $-10,5$ & 18,2 & 5,7 & $-9,0$ & 17,0 \\
\hline \multirow{4}{*}{ Çukurkışla } & MM5 & 2012 & 0,93 & 7,0 & $-7,4$ & 21,4 & 7,3 & $-8,4$ & 23,1 & 7,3 & $-9,2$ & 23,9 \\
\hline & WRF & 2013 & 0,87 & 3,2 & $-15,0$ & 13,3 & 5,4 & $-13,2$ & 15,9 & 5,4 & $-11,0$ & 14,4 \\
\hline & WRF & 2014 & 0,98 & 9,2 & $-7,2$ & 20,8 & 10,0 & $-7,1$ & 21,1 & 10,0 & $-6,6$ & 21,8 \\
\hline & WRF & 2015 & 0,98 & 6,9 & $-7,4$ & 17,3 & 8,4 & $-3,8$ & 18,8 & 8,4 & $-3,2$ & 16,8 \\
\hline
\end{tabular}

Yağışlar analiz edilmeden önce her iki havzada da gözlem yağışlarına ait çeşitli eşik yağış değerlerine göre frekans hesaplaması yapılmıştır (Tablo 6). Karasu'da yağışlı gün sayısının daha fazla olduğu görülmüştür. Karasu için her eşik artışında yağış sayısının yarılandığı söylenebilir. Her iki havzada da 2,00 mm üzeri olay sayısı farklı yıllar için oldukça azalmaktadır. Şekil 5'te de aylık toplam yağış karşılaştırmaları kutu grafiklerle birlikte sunulmuştur. Buna göre SHT verileri gözleme nazaran toplamda daha fazla yağış vermekle birlikte aynı ay için farklı yıllara ait karşılaştırmalardan da görüldüğü şekilde sistematik bir fark tespit edilememiş̧ir. Yağış verileri sıcaklık verilerine göre her güne ait değerler içermediğinden ve bir düzeltme ilişkisi bulunamadığından atmosfer model çıktısı haliyle kullanılmıştır.

Tablo 6. Eşik yağış değerlerine göre gözlem frekansı (yağış sayısı)

\begin{tabular}{|c|c|c|c|c|c|}
\hline $\begin{array}{c}\text { Eşik Yağıs } \\
\text { Değeri (mm) }\end{array}$ & Havza & $\mathbf{2 0 1 2}$ & $\mathbf{2 0 1 3}$ & $\mathbf{2 0 1 4}$ & $\mathbf{2 0 1 5}$ \\
\hline \multirow{2}{*}{$\mathbf{0 , 1 0}$} & Karasu & 90 & 52 & 92 & 93 \\
\cline { 2 - 6 } & Çukurkışla & 48 & 34 & 46 & 44 \\
\hline \multirow{2}{*}{$\mathbf{1 , 0 0}$} & Karasu & 40 & 23 & 42 & 50 \\
\cline { 2 - 6 } & Çukurkışla & 32 & 22 & 29 & 33 \\
\hline \multirow{2}{*}{$\mathbf{2 , 0 0}$} & Karasu & 20 & 11 & 29 & 39 \\
\cline { 2 - 6 } & Çukurkışla & 27 & 15 & 24 & 26 \\
\hline \multirow{2}{*}{$\mathbf{5 , 0 0}$} & Karasu & 6 & 4 & 9 & 16 \\
\cline { 2 - 6 } & Çukurkışla & 13 & 7 & 10 & 16 \\
\hline
\end{tabular}




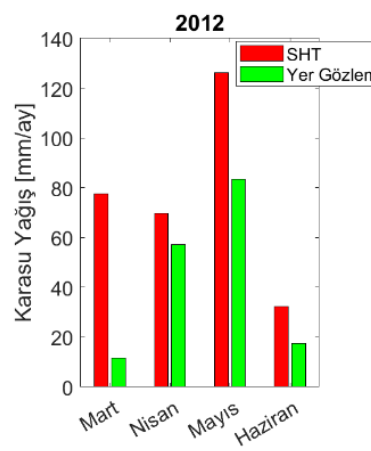

2013

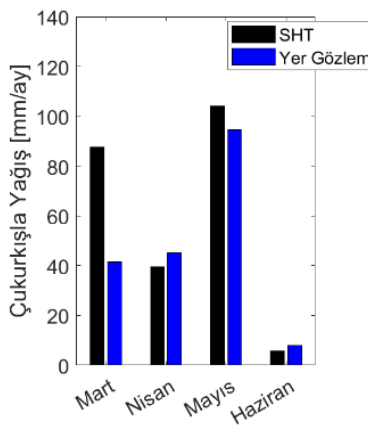

2014
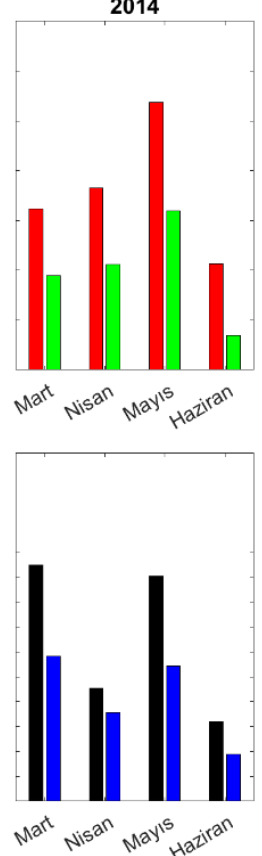

2015
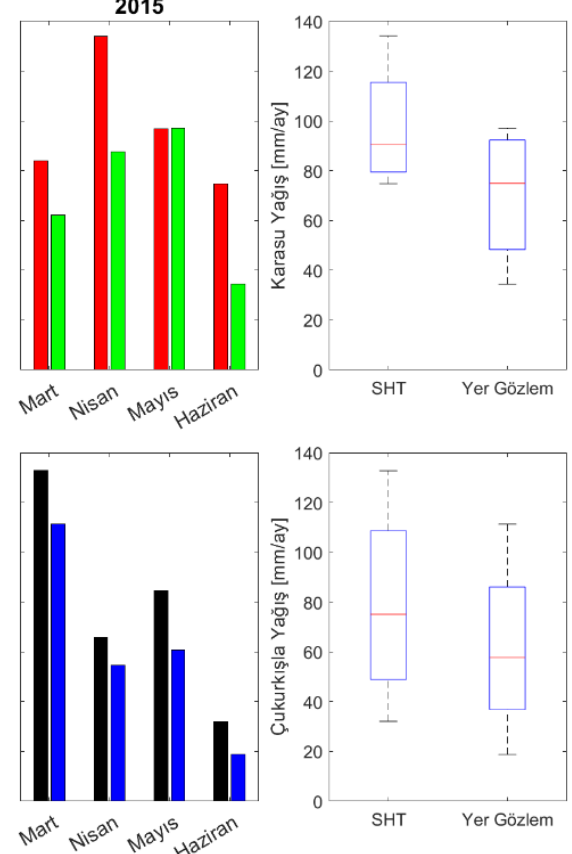

Şekil 5: Aylık toplam yağış karşılaştırması

Yağışların istatistiksel analizinde literatürde çok kullanılan algılama olasılığg (AO) hesaplanarak Tablo 7'de sunulmuştur. Oranlara göre MM5'ten WRF verisine geçişte AO'nun görece arttığı görülmektedir. Tablo 8'de eşik değeri arttıkça Yanlış Alarm Oranının (YAO) da arttığ1 görülmektedir. Üst eşiklerde YAO değerleri AO değerlerini geçmektedir. Fakat, bu oranları incelerken Tablo 9'da sunulan Sapma Oranı (SO) değerleri de önem arz etmektedir. Eşik değeri arttıkça SO da artmaktadır. Örneğin; 2013 yılında Karasu Havzası için 2 mm eşikte AO değeri 0,91 olmasına rağmen, SO değeri de 2,5 mm üzerinde olduğundan tutarlılığın düşük olduğu söylenebilir. 2013 yılından 2015'e doğru SO’ların yıllar içinde Karasu havzasında azalırken Çukurkışla havzasında görece sabit kaldığı gözlenmektedir.

Tablo 7: SHT yağış verisi farklı eşik yağışlar için yakalama olasılıkları (YO)

\begin{tabular}{|c|c|c|c|c|c|c|}
\hline $\begin{array}{c}\text { Eşik Yağış } \\
\text { Değeri (mm) }\end{array}$ & Havza & $\begin{array}{c}\mathbf{2 0 1 2} \\
\text { MM5 }\end{array}$ & $\begin{array}{c}\mathbf{2 0 1 3} \\
\text { WRF }\end{array}$ & $\begin{array}{c}\mathbf{2 0 1 4} \\
\text { WRF }\end{array}$ & $\begin{array}{c}\mathbf{2 0 1 5} \\
\text { WRF }\end{array}$ & $\begin{array}{c}\mathbf{2 0 1 3 - 2 0 1 5} \\
\text { WRF }\end{array}$ \\
\hline \multirow{2}{*}{$\mathbf{0 , 1 0}$} & Karasu & 0,86 & 0,90 & 0,86 & 0,86 & 0,87 \\
\cline { 2 - 7 } & Çukurkışla & 0,81 & 0,94 & 0,78 & 0,89 & 0,87 \\
\hline \multirow{2}{*}{$\mathbf{1 , 0 0}$} & Karasu & 0,80 & 0,96 & 0,86 & 0,82 & 0,86 \\
\cline { 2 - 7 } & Çukurkışla & 0,69 & 0,59 & 0,62 & 0,77 & 0,68 \\
\hline \multirow{2}{*}{$\mathbf{2 , 0 0}$} & Karasu & 0,70 & 0,91 & 0,79 & 0,84 & 0,84 \\
\cline { 2 - 7 } & Çukurkişla & 0,52 & 0,53 & 0,52 & 0,78 & 0,66 \\
\hline \multirow{2}{*}{$\mathbf{5 , 0 0}$} & Karasu & 0,50 & 0,75 & 0,57 & 0,80 & 0,73 \\
\cline { 2 - 7 } & Çukurkışla & 0,23 & 0,29 & 0,33 & 0,58 & 0,48 \\
\hline
\end{tabular}


Tablo 8: SHT yağış verisi farklı eşik yağışlar için yanlış alarm oranları (YAO)

\begin{tabular}{|c|l|c|c|c|c|c|}
\hline $\begin{array}{c}\text { Eşik Yağıs } \\
\text { Değeri (mm) }\end{array}$ & \multicolumn{1}{|c|}{ Havza } & $\begin{array}{c}\mathbf{2 0 1 2} \\
\text { MM5 }\end{array}$ & $\begin{array}{c}\mathbf{2 0 1 3} \\
\text { WRF }\end{array}$ & $\begin{array}{c}\mathbf{2 0 1 4} \\
\text { WRF }\end{array}$ & $\begin{array}{c}\mathbf{2 0 1 5} \\
\text { WRF }\end{array}$ & 2013-2015 WRF \\
\hline \multirow{2}{*}{$\mathbf{0 , 1 0}$} & Karasu & 0,09 & 0,14 & 0,20 & 0,14 & 0,16 \\
\cline { 2 - 7 } & Cukurkışla & 0,35 & 0,33 & 0,39 & 0,21 & 0,30 \\
\hline \multirow{2}{*}{$\mathbf{1 , 0 0}$} & Karasu & 0,48 & 0,50 & 0,48 & 0,35 & 0,44 \\
\cline { 2 - 7 } & Çukurkışla & 0,49 & 0,55 & 0,56 & 0,31 & 0,44 \\
\hline \multirow{2}{*}{$\mathbf{2 , 0 0}$} & Karasu & 0,71 & 0,67 & 0,62 & 0,36 & 0,53 \\
\cline { 2 - 7 } & Çukurkışla & 0,60 & 0,67 & 0,65 & 0,36 & 0,52 \\
\hline \multirow{2}{*}{$\mathbf{5 , 0 0}$} & Karasu & 0,87 & 0,81 & 0,82 & 0,57 & 0,71 \\
\cline { 2 - 7 } & Çukurkışla & 0,88 & 0,89 & 0,87 & 0,53 & 0,73 \\
\hline
\end{tabular}

Tablo 9: SHT yağıs verisi farklı eşik yağışlar için sapma oranları (SO)

\begin{tabular}{|c|l|c|c|c|c|c|}
\hline $\begin{array}{c}\text { Eşik Yağış } \\
\text { Değeri (mm) }\end{array}$ & Havza & $\begin{array}{c}\mathbf{2 0 1 2} \\
\text { MM5 }\end{array}$ & $\begin{array}{c}\mathbf{2 0 1 3} \\
\mathbf{W R F}\end{array}$ & $\begin{array}{c}\mathbf{2 0 1 4} \\
\mathbf{W R F}\end{array}$ & $\begin{array}{c}\mathbf{2 0 1 5} \\
\text { WRF }\end{array}$ & 2013-2015 WRF \\
\hline \multirow{2}{*}{$\mathbf{0 , 1 0}$} & Karasu & 0,94 & 1,04 & 1,09 & 1,00 & 1,00 \\
\cline { 2 - 7 } & Cukurkışla & 1,25 & 1,41 & 1,28 & 1,14 & 1,14 \\
\hline \multirow{2}{*}{$\mathbf{1 , 0 0}$} & Karasu & 1,55 & 1,91 & 1,65 & 1,27 & 1,27 \\
\cline { 2 - 7 } & Çukurkışla & 1,34 & 1,32 & 1,38 & 1,11 & 1,11 \\
\hline \multirow{2}{*}{$\mathbf{2 , 0 0}$} & Karasu & 2,45 & 2,73 & 2,08 & 1,32 & 1,32 \\
\cline { 2 - 7 } & Çukurkışla & 1,30 & 1,60 & 1,48 & 1,22 & 1,22 \\
\hline \multirow{2}{*}{$\mathbf{5 , 0 0}$} & Karasu & 3,83 & 4,00 & 3,14 & 1,87 & 1,87 \\
\cline { 2 - 7 } & Çukurkışla & 1,85 & 2,57 & 2,56 & 1,25 & 1,25 \\
\hline
\end{tabular}

\subsection{MM5/WRF Akım Tahmini Uygulamaları}

Geçmiş dönem tahmin simülasyonu, her zaman aralığında, o zamana kadar mevcut olan veri ile 1sıtma (warm-up) yaparak ileri günler için SHT verilerini girdi alan tahminde bulunmaktadır. Çalışmanın bu kısmında düzeltilmiş MM5/WRF SHT verileri kullanılarak geçmiş dönem tahmin simülasyon sistemi ile üretilen akım tahminleri sunulmaktadır. Burada her adımda model kapalı döngü ile çalıştırılarak 2 günlük tahmin üretilmiş ve en son tüm tahminler 2 grupta sınıflandırılarak tek bir zaman serisi olarak sunulmuştur. Karasu ve Çukurkışla Havzalarında 2012 - 2015 yılları (1. ve 2. tahmin günü) için elde edilen günlük akım tahmin sonuçları gözlemlerle kıyaslanarak Şekil 5 ve Şekil 6'da sunulmuştur. Ayrıca Tablo 10'da model performansları verilmiş̧tir. Modellerin uygulandığı zaman aralı̆̆ı, kar erime dönemi olan 01 Mart - 30 Haziran tarihleri arasıdır. Daha sonra tahmin sonuçlarının yine 1. (24-saat) ve 2. tahmin (48-saat) günleri için istatistiksel performans değerlendirmesi yapılmıştır. SHT verisi ile yapılan akım tahminlerinde, tahmin başlangıç zaman dilimine kadar gözlem değerlerine (gözlenmiş yağış ve sıcaklık) bağlı olarak simülasyon yapılmakta ve sonraki günler için akım tahmini hesaplanmaktadır. $\mathrm{Bu}$ tahmin yapıs1 her gün güncellenmektedir; Q1.Gün ve Q2.Gün bu tahminleri göstermektedir.

Her iki uygulama havzası için de WRF kullanılan yıllardaki akım tahminlerinin, MM5 kullanılan 2012 yılına kıyasla gözlenen akımlarla daha tutarlı sonuçlar verdiği görülmektedir. Deterministik tahminlerde, beklenildiği gibi 1. tahmin günündeki tutarlılıklar genelde 2. tahmin gününden daha yüksek olmaktadır. Yağmur potansiyeli daha yüksek olan Çukurkışla Havzasında, 2. tahmin günündeki yağış tutarsızlıkları nedeniyle model performansında düşüş gözlenmiştir (Şekil 6).

Karasu Havzasında elde edilen akım tahminlerinde hidrografların yükselme zamanlarını ve eğilimlerini yakaladığ 1 görülmektedir. Çekilme zamanlarındaki tutarlılık 2012 yılında en düşük, 2015 yılında ise en yüksektir. Nispeten erken erimenin gözlendiği 2013 yılında yağış tahminlerinin ilk piki yakalamak için yetersiz kaldığı görülmektedir. 2014 yılında ise gözlemlerde oldukça düşük akımlı ekstrem bir yıl gözlemlenmiş ve görece yüksek bir başarı oranı ile tahmin performansı elde edilmiştir. 2015 yılı erime döneminde, kar çekilme eğrilerinin uzun yıllar ortalamasına çok yakın olması, erime döneminde etkili yağı̧̧ların çok gözlenmemesi gibi sebeplerin de etkisiyle; akım tahmin sonuçları önceki yıllara göre daha yüksek bir performans ile yakalanmıştır. SHT verileri yağış tahminlerini gözlenenden daha erken bir zamanda ve daha yüksek miktarda öngördüğü için model uygulamasında, ilk akım pikinin zamansal olarak daha erken ve büyük bir değerde gerçekleşmesine sebep olmaktadır. 
Çukurkışla Havzasında 2012 yılında akım tahminlerinin sonuçları incelendiğinde model performans göstergeleri çok düşük olmamakla birlikte özellikle erime sezonun başındaki tutarlılıkların nispeten az olduğu görülmektedir. 2013 yılındaki akım değerleri diğer iki yıldan daha düşüktür, erimeye bağlı olduğu düşünülen ilk pik daha yüksek tutarlılıkla olmakla birlikte, yağışa bağlı pik akımların da yakalanabildiği gözlenmiştir. Çukurkışla Havzasında da 2014 yılı akımları düşük olmakla birlikte yakalanan pik akımdan da ötürü başarı oranı Karasu’ya göre daha yüksektir. 2015 yılındaki akım tahminlerinin yüksek bir model performansı ile elde edildiği tespit edilmiştir. 2015 yılında her iki havzada da çekilme kısmında gözlenenlerle oldukça uyumlu sonuçlar vermiştir.

Kar erimesinin ve modellemesinin etkin olduğu bu tür çalışmalarda yağışların yanı sıra sıcaklık da özellikle erime dönemlerinde büyük bir önem arz etmektedir. Bu sebeple, sıcaklıktaki tutarlılıkların kar erimesi döneminde akım tahmin performanslarını etkilediği ve tutarlılığını arttırdığı gözlenmiştir.
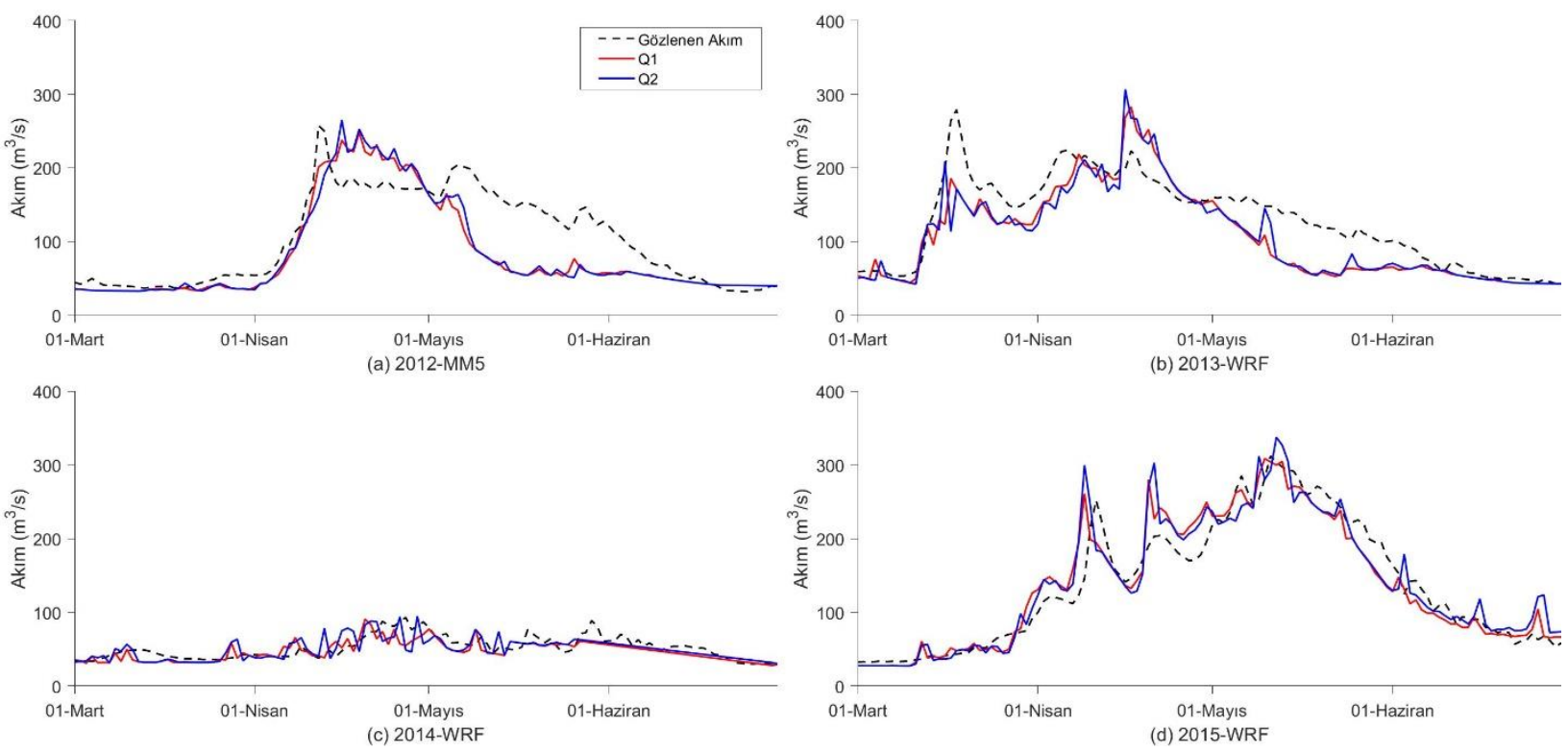

Şekil 5: Karasu Havzası hidrolojik model tahmin sonuçları
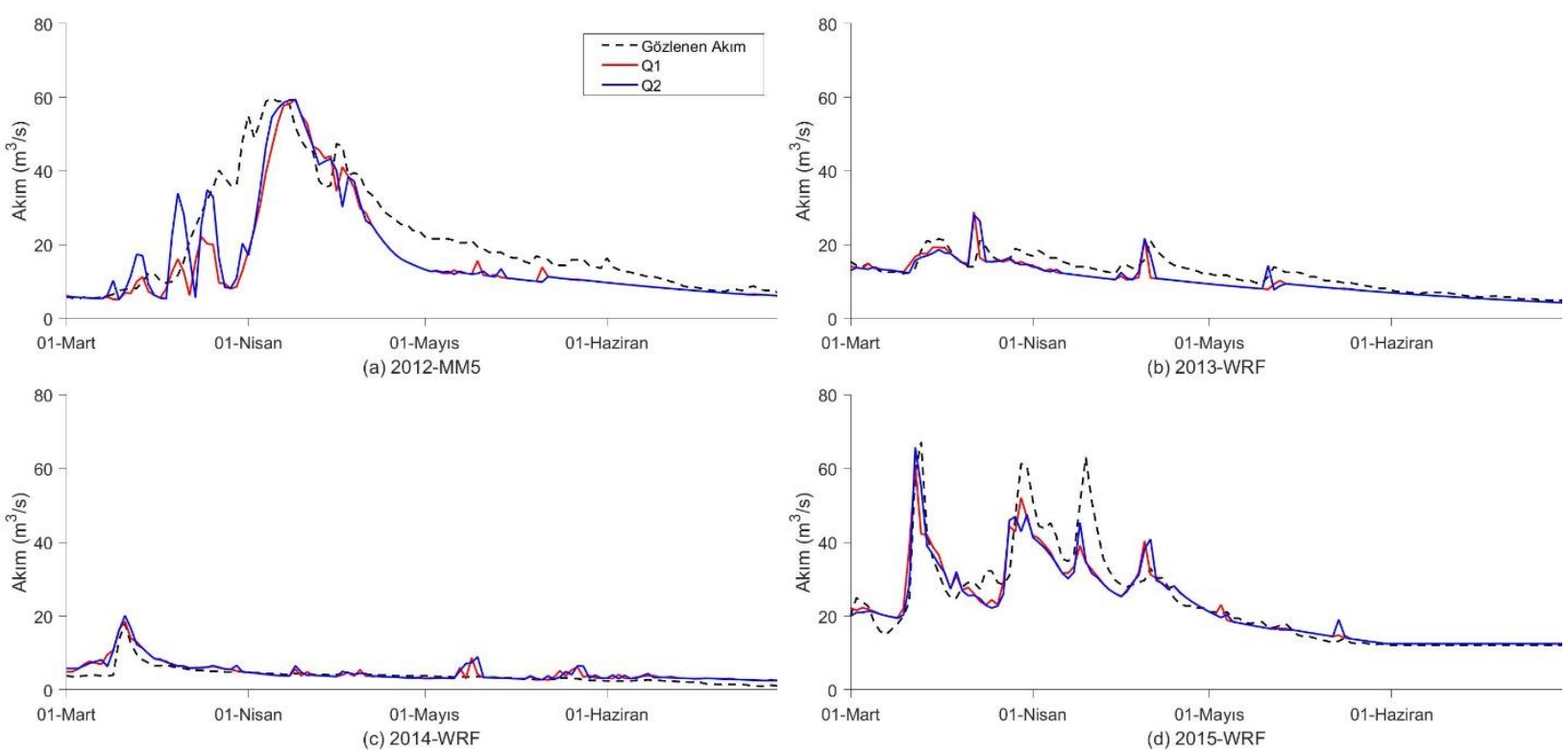

Şekil 6: Çukurkışla Havzası hidrolojik model tahmin sonuçları 
Tablo 10: Hidrolojik model tahmin simülasyon performansları

\begin{tabular}{|c|c|c|c|c|c|c|c|c|c|c|}
\hline \multirow{2}{*}{$\begin{array}{l}\text { Tahmin } \\
\text { Ufku } \\
\text { (saat) }\end{array}$} & \multirow[b]{2}{*}{ SHT } & \multirow[b]{2}{*}{ Yll } & \multicolumn{4}{|c|}{ Karasu } & \multicolumn{4}{|c|}{ Çukurkışla } \\
\hline & & & $\mathbf{R}^{2}$ & NSE & $\underset{\left(\mathbf{m}^{3} / \mathbf{s}\right)}{\text { RME }}$ & $\begin{array}{l}\text { MAE } \\
\left(\mathbf{m}^{3} / \mathbf{s}\right)\end{array}$ & $\mathbf{R}^{2}$ & NSE & $\begin{array}{c}\text { RMSE } \\
\left(\mathbf{m}^{3} / \mathbf{s}\right)\end{array}$ & $\begin{array}{l}\text { MAE } \\
\left(\mathbf{m}^{3} / \mathbf{s}\right)\end{array}$ \\
\hline \multirow{4}{*}{24} & MM5 & 2012 & 0,64 & 0,47 & 44,37 & 31,75 & 0,72 & 0,58 & 9,66 & 6,44 \\
\hline & \multirow{3}{*}{ WRF } & 2013 & 0,75 & 0,59 & 37,42 & 28,80 & 0,72 & 0,56 & 2,90 & 2,10 \\
\hline & & 2014 & 0,57 & 0,47 & 11,11 & 5,51 & 0,77 & 0,54 & 1,54 & 1,07 \\
\hline & & 2015 & 0,90 & 0,90 & 26,53 & 18,86 & 0,84 & 0,82 & 5,52 & 3,01 \\
\hline \multirow{4}{*}{48} & MM5 & 2012 & 0,63 & 0,45 & 45,16 & 32,47 & 0,71 & 0,61 & 9,33 & 6,37 \\
\hline & \multirow{3}{*}{ WRF } & 2013 & 0,72 & 0,55 & 39,09 & 29,21 & 0,74 & 0,59 & 2,80 & 2,09 \\
\hline & & 2014 & 0,44 & 0,34 & 12,35 & 9,2 & 0,78 & 0,47 & 1,65 & 1,18 \\
\hline & & 2015 & 0,87 & 0,87 & 30,31 & 21,25 & 0,85 & 0,83 & 5,30 & 3,01 \\
\hline
\end{tabular}

\section{Sonuç ve Öneriler}

$\mathrm{Bu}$ çalışmada, ülkemizde ve dünyada gün geçtikçe önem kazanan ve uygulayıcıların ihtiyaç duyduğu gerçek zamanlı atmosferik-hidrolojik model entegrasyonu ile hidrolojik tahmin sistemi kurgulanmıştır. Bu bağlamda öncelikle SHT verileri yer gözlem verileriyle karşılaştırılmıştır. WRF tahmini sıcaklık için yüksek tutarlılık vermekte ve tüm sezonda göreceli sabit bir ilişki ortaya koymaktadır. Bu nedenle düzeltme çalışmaları tutarlılık performansını arttırmıştır. Öte yandan, yağış verileri sıcaklık verileri gibi sürekli olmayıp her güne ait çok değişken bir değere sahip olabildiğinden karşılaştırma yapmak daha zordur ve tutarlılık daha düşüktür. Karşılaştırma kriterlerinde literatürde de çok kullanılan yakalama oranlarına başvurulmuştur. Oranlara göre MM5'ten WRF verisine geçişte yakalama oranlarının görece arttı̆̆ söylenebilir. Fakat, bu oranları incelerken sapma değerleri de önem arz etmektedir.

Çalışmada dağlık alanlardaki yağış-akış ilişkisini temsil etmek için kavramsal bir hidrolojik modelin (HBV) uygulaması yapılmıştır. Model öncelikle yer verisine göre kalibrasyon/doğrulama işlemlerinden geçirilmiş ve ardından tahmin aşaması için kısmi düzeltilmiş SHT verisi girdi olarak kullanılmıştır. Seçilen havzaların özellikleri gözetildiğinde geçmiş dönem tahmin simülasyon kurgusu kısa vadeli olarak (1-2 gün) özellikle kar erime periyodu (01 Mart-30 Haziran) aralığında çalıştırılmıştır. Bu aralıktaki tahmin başarısı akım değerlerindeki zamanlama ve tutarlılık performansına doğrudan bağlıdır. Yapılan çalışmasında yenilenen atmosferik model çıktılarının görece daha başarılı SHT verisi üretebildiği gözlenmiştir. Özellikle 2015 su yılı akım tahminlerinin her iki havzada da oldukça başarılı performans vermesi ileriye dönük yapılacak çalışmalarda önemli motivasyon yaratmıştır. Bu çalışmada geriye dönük gerçek zamanlı bir tahmin sistemi kurgulanmış ve başarılı sayılabilecek sonuçlar elde edilmiştir. Çalışma sonuçları hem kamu/özel sektör uygulamacılarına yön verebilecek, aynı zamanda da bilimsel literatüre katkı sağlayacaktır.

Aşağıda çalışmanın gelişmeye açık yönleri ve öneriler sıralanmıştır:

- Ölçüm ağının temsil yeteneği çok önemli olduğu için, yeni teknolojilerle donanmış otomatik yer gözlem istasyonlarının sayısının arttırılması gerekmektedir. Öte yandan, sadece istasyon sayısının artması değil ama gerçek zamanlı veri transferi ve bakım/onarım konuları da önem kazanmaktadır. Sonuçta, gerçek zamanlı akım tahmini, araziden eş zamanlı ve sürekli olarak alınan verilere dayanmaktadır.

- Hidrolojik model uygulamalarında kullanılmadan önce SHT'lerin doğruluk ve düzeltme analizlerinin gerçekleştirilmesi gerekmektedir. Son kullanıcı açısından en avantajlı durum, diğer uluslararası kuruluşlarda olduğu gibi düzeltilmiş sayısal hava tahminlerinin ilgili kurum tarafindan sağlanması olacaktır.

- Kısa ve uzun vadeli günlük akım tahminlerinde, gözlem verileri ile yapılan güncellemeler model sonuçlarını iyileştirmekte ve performansı yükseltmektedir. Bu nedenle, bu çalışmanın veri asimilasyonu yöntemleri ile geliştirilmesi ve iyileştirilmesi gerekmektedir.

- Çoklu model anlayışı ve belirsizlik azaltma gibi sebeplerle, kavramsal modellerin yanı sıra, fiziksel ve veri güdümlü modellerin de uygulanması ve karşılaştırması faydalı olacaktır.

- Hidrolojik model çıktılarının gelişen uydu teknolojileriyle desteklenmesi (kar, toprak nemi) akım tahminlerinin iyileştirilmesine katkı sağlayabilir. 
- Bu çalışma, üretilen akım tahminlerinin kısa dönemli hazne işletme çalışmalarında değerlendirilmesi yönünde genişletilmelidir. Bu durum, su ve enerji kaynaklarının optimum işletilmesini sağlayacak ve ülke ekonomisine değerli bir katkı olacaktır.

- İleriki çalışmalarda, güncel teknolojiye paralel olarak deterministik tahminler yerine orta vadeli ensemble (demet) tahmin verisi test edilerek tahmin sistemi performans karşılaştırması yapılabilir.

\section{Teşekkür}

Bu çalışma 113 Y075 numaralı TÜBİTAK projesi ve ES1404 aksiyon numaralı COST projesi kapsamında desteklenmiştir. Veri paylaşımı için Devlet Su İşleri (DSI) ve Meteoroloji Genel Müdürlüğüne (MGM) teşekkür ederiz.

\section{Kaynaklar}

Albostan A., Önöz B., (2010), Seasonality measurement of low-flows: Mid-Euphrates Basin example, 9th Advances in Civil Engineering Conference (ACE 2010)'in İçinde, September 27-30, Karadeniz Technical University, Trabzon, Turkey.

Anderson M.L., Chen Z.Q., Kavvas M.L., Feldman A., (2002), Coupling HEC-HMS with atmospheric models for prediction of watershed runoff, Journal of Hydrologic Engineering, 7(4), 312-318.

Belair S., Roch M., Leduc A.M., Vaillancourt P.A., Laroche S., Mailhot J., (2009), Medium-range quantitative precipitation forecasts from Canada's new 33-km deterministic global operational system, Weather and Forecasting, 24(3), 690-708.

Bergström S., (1976), Development and application of a conceptual runoff model for Scandinavian catchments, Doktora Tezi, SMHI Reports RHO No. 7, Norrköping.

Bergström S., Lindström G., (2015), Interpretation of runoff processes in hydrological modelling-experience from the HBV approach, Hydrological Processes, 29(16), 3535-3545.

Buhan S., Kucuk D., Cinar M.S., Güvengir U., Demirci T., Yilmaz Y., ...Yildirim M.U., (2019), A Scalable River Flow Forecast and Basin Optimization System for Hydropower Plants, IEEE Transactions on Sustainable Energy, doi: 10.1109/TSTE.2019.2952450.

Casati B., Wilson L.J., Stephenson D.B., Nurmi P., Ghelli A., Pocernich M., ...Mason S., (2008), Forecast verification: current status and future directions, Meteorological Applications: A journal of forecasting, practical applications, training techniques and modelling, 15(1), 3-18.

Cuo L., Pagano T.C., Wang Q.J., (2011), A review of quantitative precipitation forecasts and their use in short-to medium-range streamflow forecasting, Journal of hydrometeorology, 12(5), 713-728.

Çakmak Ö., Temiz Ö., Baran T., (2010), Dicle Havzası Billoris AGİ yıllık ve aylık akımların stokastik modellenmesi, VI. Ulusal Hidroloji Kongresi, 22-24 Eylül, Pamukkale Üniversitesi, Denizli.

Durai V.R., Bhradwaj R., (2014), Evaluation of statistical bias correction methods for numerical weather prediction model forecasts of maximum and minimum temperatures, Natural Hazards, 73(3), 1229-1254.

Ebert E.E., Damrath U., Wergen W., Baldwin M.E., (2003), The WGNE assessment of short-term quantitative precipitation forecasts, Bulletin of the American Meteorological Society, 84(4), 481-492.

El Khalki E.M., Tramblay Y., Amengual A., Homar V., Romero R., Saidi M.E.M., Alaouri M., (2020), Validation of the AROME, ALADIN and WRF Meteorological Models for Flood Forecasting in Morocco, Water, 12(2), 437, doi: 10.3390/w12020437.

Finger D., Vis M., Huss M., Seibert J., (2015), The value of multiple data set calibration versus model complexity for improving the performance of hydrological models in mountain catchments, Water Resources Research, 51, 1939-1958.

Gallus Jr W.A., Segal M., (2001), Impact of improved initialization of mesoscale features on convective system rainfall in 10-km Eta simulations, Weather and Forecasting, 16(6), 680-696.

Ghajarnia N., Liaghat A., Arasteh P.D., (2015), Comparison and evaluation of high resolution precipitation estimation products in Urmia Basin-Iran, Atmospheric Research, 158, 50-65.

Givati A., Gochis D., Rummler T., Kunstmann H., (2016), Comparing one-way and two-way coupled hydrometeorological forecasting systems for flood forecasting in the Mediterranean region, Hydrology, 3(2), 19, doi: 10.3390/hydrology3020019.

Habets F., LeMoigne P., Noilhan J., (2004), On the utility of operational precipitation forecasts to served as input for streamflow forecasting, Journal of Hydrology, 293(1-4), 270-288.

Hamill T.M., (1999), Hypothesis tests for evaluating numerical precipitation forecasts, Weather and Forecasting, 14(2), $155-167$.

Immerzeel W.W., Lutz A.F., Andrade M., Bahl A., Biemans H., Bolch T., ... Baillie J.E.M., (2020), Importance and vulnerability of the world's water towers, Nature, 577(7790), 364-369.

Johansson B., Caves R., Ferguson R., Turpin O., (2001), Using remote sensing data to update the simulated snow pack of the HBV runoff model, IAHS PUBLICATION, 595-597.

Jolliffe I.T., Stephenson D.B. (Eds.), (2012), Forecast verification: a practitioner's guide in atmospheric science, John Wiley and Sons.

Jónsdóttir J.F., Sórarinsson J.S., (2004), Comparison of HBV models driven with weather station data and with MM5 meteorological model data, Orkustofnun Hydrological Services, Report No. OS-2004/017.

Kunstmann H., Stadler C., (2005), High resolution distributed atmospheric-hydrological modelling for Alpine catchments, Journal of hydrology, 314(1-4), 105-124.

Mailhot J., Bélair S., Lefaivre L., Bilodeau B., Desgagné M., Girard C., ...Qaddouri A., (2006), The 15-km version of the Canadian regional forecast system, Atmosphere-Ocean, 44(2), 133-149.

Martinec, J. (1975) Snowmelt-Runoff Model for stream flow forecasts. Nordic Hydrology, 6(3), 145-154.

Martinec J., Rango A., Roberts R., (1998), The Snowmelt Runoff Model (SRM) User's Manual, Geographica Bernensia, P29, Department of Geography, University of Berne, Berne, Switzerland. 
Özdemir O., (2001), Çok amaçlı ardışık barajların işletilmesi, Gazi Üniversitesi Mühendislik Mimarlık Fakültesi Dergisi, 16(2), 5361.

Pangali Sharma T.P., Zhang J., Khanal N.R., Prodhan F.A., Paudel B., Shi L., Nepal N., (2020), Assimilation of Snowmelt Runoff Model (SRM) using Satellite Remote Sensing Data in Budhi Gandaki River Basin, Nepal, Remote Sensing, (12), 1951, doi: $10.3390 / \mathrm{rs} 12121951$

Rossa A., Liechti K., Zappa M., Bruen M., Germann U., Haase G., ... Krahe P., (2011), The COST 731 Action: A review on uncertainty propagation in advanced hydro-meteorological forecast systems, Atmospheric Research, 100(2-3), 150-167.

Selek B., Yazici D.D., Aksu H., Özdemir A.D., (2016), Seyhan Dam, Turkey, and climate change adaptation strategies, In Increasing Resilience to Climate Variability and Change (pp. 205-231). Springer, Singapore.

Sen O.L., Unal A., Bozkurt D., Kindap T., (2011), Temporal changes in the Euphrates and Tigris discharges and teleconnections, Environmental Research Letters, 6(2), 024012, doi:10.1088/1748-9326/6/2/024012.

Sharifi E., Steinacker R., Saghafian B., (2018), Multi time-scale evaluation of high-resolution satellite-based precipitation products over northeast of Austria, Atmospheric Research, 206, 46-63.

Shirali E., Shahbazi A.N., Fathian H., Zohrabi N., Hassan E.M., (2020), Evaluation of WRF and artificial intelligence models in shortterm rainfall, temperature and flood forecast (case study), Journal of Earth System Science, 129(1), 1-16.

SMHI, (1996), IHMS: Integrated hydrological modeling system manual, Version 4.0. Swedish Meteorological and Hydrological Institute, Norrköping, Sweden.

Shrestha D.L., Robertson D.E., Wang Q.J., Pagano T.C., Hapuarachchi, H.A.P., (2013), Evaluation of numerical weather prediction model precipitation forecasts for short-term streamflow forecasting purpose, Hydrology and Earth System Sciences, 17(5), 1913. doi:10.5194/hess-17-1913-2013.

Şensoy A., Uysal G., (2012), The value of snow depletion forecasting methods towards operational snowmelt runoff estimation using MODIS and Numerical Weather Prediction Data, Water Resources Management, 26(12), 3415-3440.

Şorman A.A., Şensoy A. Tekeli A.E., Şorman A.Ü., Akyürek, Z., (2009), Modelling and forecasting snowmelt runoff process using the HBV model in the eastern part of Turkey, Hydrological Processes: An International Journal, 23(7), 1031-1040.

Şorman A.A., Uysal G., Şensoy A., (2019), Probabilistic snow cover and ensemble streamflow estimations in the Upper Euphrates Basin, Journal of Hydrology and Hydromechanics, 67(1), 82-92, doi: 10.2478/johh-2018-0025.

Tahir A.A., Chevallier, P., Arnaud, Y., Neppel, L., Ahmad, B., (2011), Modeling snowmelt-runoff under climate scenarios in the Hunza River Basin, Karakoram Range, Northern Pakistan, Journal of Hydrology, 409, 104-117.

Taşdemir G., (2009), Uzaktan algılama ve Coğrafi Bilgi Sistemlerinin birlikte kullanılması ile kar erimesi akış hidrografinın benzetimi (Sarız Çayı Havzası örneği), Yüksek Lisans Tezi, Gazi Üniversitesi, Fen Bilimleri Enstitüsü, Ankara.

te Linde A.H., Aerts J.C.J.H., Hurkmans R.T.W.L., Eberle M., (2008), Comparing model performance of two rainfall-runoff models in the Rhine basin using different atmospheric forcing data sets, Hydrology and Earth System Sciences, 12, 943-957.

URL-1, (2020), https://www.mmm.ucar.edu/weather-research-and-forecasting-model, [Erişim 15 Kasım 2020].

Uysal G., Şensoy A., Şorman, A.A., (2016), Improving daily streamflow forecasts in mountainous Upper Euphrates basin by multilayer perceptron model with satellite snow products, Journal of Hydrology, 543, 630-650.

Werner M., Schellekens J., Gijsbers P., van Dijk M., van den Akker O., Heynert K., (2013), The Delft-FEWS flow forecasting system, Environmental Modelling \& Software, 40, 65-77.

WMO, (1986), Intercomparison of models of snowmelt runoff, Publication No. 646, Operational Hydrology Report No. 23, World Meteorological Organization, Geneva, Switzerland. 